\title{
Effects of fenoterol on ventilatory responses to hypoxia and hypercapnia in normal subjects
}

\author{
Yasuhiro Yoshiike, Shunsuke Suzuki, Yuuji Watanuki, Takao Okubo
}

\begin{abstract}
Background - The effects of $\beta_{2}$ adrenergic agonists on chemoreceptors remain controversial. This study was designed to examine whether fenoterol, a $\beta_{2}$ adrenergic agonist, increases the ventilatory responses to hypercapnia (HCVR) and hypoxia (HVR) in normal subjects.

Methods - HCVR was tested with a rebreathing method and HVR was examined with a progressive isocapnic hypoxic method in 11 normal subjects. Both HCVR and HVR were assessed by the slope of occlusion pressure $\left(\mathbf{P}_{0.1}\right)$ or ventilation ( $\dot{V} E)$ plotted against end tidal carbon dioxide pressure and arterial oxygen saturation, respectively. Respiratory muscle strength, spirometric values and lung volume were measured. After a single oral administration of $5 \mathrm{mg}$ fenoterol or placebo HCVR and HVR were evaluated.

Results - Fenoterol treatment did not change the specific airway conductance or forced expiratory volume in one second. Respiratory muscle strength did not change. Fenoterol increased the slope of the HCVR of both $P_{0.1}$ (from $0.251(0 \cdot 116)$ to $0.386(0.206) \mathrm{kPa} / \mathrm{kPa}$, average increase $71 \%)$ and $\dot{V} E$ (from $10.7(3.4)$ to $15 \cdot 1(4 \cdot 2)$ $1 / \mathrm{min} / \mathrm{kPa}$, average increase $52 \%$, and shifted the response curves to higher values. For the HVR fenoterol increased the slopes of both $P_{0.1}$ and $\dot{V} E$ (from -4.06 $(2.00) \times 10^{-3}$ to $-7.99(4.29) \times 10^{-3} \mathrm{kPa}$ $\%$, an average increase of $83 \%$, and from $-0.221(0.070)$ to $-0.313(0.112) 1 / \mathrm{min} / \%$, a $44.5 \%$ increase, respectively), and shifted the response curves to higher values.

Conclusion - Acute administration of fenoterol increases the ventilatory responses to both hypercapnia and hypoxia in normal subjects.
\end{abstract}

(Thorax 1995;50:139-142)

The First Department of Internal Medicine, Yokohama City

University School

of Medicine,

3-9 Fukuura,

Kanazawa-ku,

Yokohama 236, Japan

Y Yoshiike

S Suzuki

Y Watanuki

T Okubo

Reprint requests to: Dr S Suzuki.

Received 21 January 1994

Returned to authors

Returned to april 1994

26 April 1994

Revised version
6 July 1994

6 July 1994

2 November 1994

Keywords: fenoterol, $\beta$ adrenergic agonist, hypercapnic ventilatory response, hypoxic ventilatory response.

Isoprenaline, a potent $\beta$ adrenergic agonist, is known to induce hyperpnoea ${ }^{1-4}$ although the mechanisms underlying this are disputed. Heistad $e t a l^{1}$ and Winn et $a l^{4}$ showed that intravenous isoprenaline increased ventilation by stimulation of the peripheral chemoreceptors and ventilation was augmented by moderate hypoxia. Wasserman $e t a l^{\beta}$ found that bilateral sectioning of the carotid sinus nerves substantially decreased the ventilatory response to isoprenaline. Eldridge and Gill-Kumar ${ }^{5}$ and
Lahiri et $a l^{6}$ directly measured the carotid chemoreceptor activity and showed that isoprenaline excited the carotid body. Thus, isoprenaline acts on the $\beta$ adrenergic receptors of the carotid body and increases ventilation.

The effects of $\beta_{2}$ adrenergic agonists on the central chemoreceptors remain controversial. Some studies ${ }^{78}$ showed that $\beta_{2}$ adrenergic agonists potentiate ventilatory chemosensitivity, but this was not a universal finding ${ }^{9}$ and this discrepancy may result from a species difference. Furthermore, little is known about the effects of $\beta_{2}$ adrenergic agonists on the ventilatory response to hypoxia. It may be necessary to consider the effects of $\beta_{2}$ agonists on ventilatory control when treating patients with airways obstruction. The purpose of the present study was to investigate the quantitative effects of fenoterol, a $\beta_{2}$ adrenergic agonist, on ventilatory responses to hypercapnia and hypoxia in normal subjects.

\section{Methods}

SUBJECTS

Eleven healthy non-smoking men whose mean (SD) age was 29.0 (6.2) years (range 24-46 years) participated in the study. All were medical personnel and had no history of chronic respiratory or circulatory diseases. All gave informed consent and the study was approved by the institution's committee on investigation in humans.

\section{PULMONARY FUNCTION TESTS}

Spirometric measurements (forced expiratory volume in one second $\left(\mathrm{FEV}_{1}\right)$ and vital capacity (VC)) were performed using a dry seal spirometer (OST-80, Chest Co, Tokyo) and body plethysmography (Autobox 2800, Gould, USA) was used to measure specific airway conductance (sGaw) and functional residual capacity (FRC).
VENTILATORY RESPONSES TO HYPERCAPNIA AND HYPOXIA

Chemical control of breathing was assessed by measuring minute ventilation $(\dot{V} E)$ and occlusion pressure $\left(\mathrm{P}_{0.1}\right)$ responses to hypercapnia or hypoxia. Response to hypercapnia (HCVR) was measured by a modification of the Read technique. ${ }^{10}$ The circuit used was similar to that of Whitelaw et al. ${ }^{11} \mathrm{~A}$ two way non-rebreathing valve (Hans-Rudolph no. 1400, Kansas City, USA) was attached to the mouthpiece; both inspiratory and expiratory sides of the valve 
were connected to the rebreathing bag. Mouth pressure was measured from the side tap of the mouthpiece using a differential pressure transducer (MP-45 Validyne, Northridge, USA). Airflow was measured with a Fleisch pneumotachograph (Fleisch no. 1, Lausanne, Switzerland) placed between the mouthpiece and the two way valve. The volume was obtained from electrical integration of the flow signal. The inspiratory side of the two way valve was connected with a solenoid valve which was capable of occluding the side of the valve. The solenoid valve was closed during expiration and opened no later than $200 \mathrm{~ms}$ after the beginning of inspiration using an analog electrical circuit, by which a breathing cycle for measurement of occlusion pressure was manually selected. Occlusion pressure $\left(P_{0.1}\right)$ was obtained from the pressure measured $100 \mathrm{~ms}$ after the onset of inspiration, as defined by the appearance of a negative mouth pressure. The expiratory side was sampled continuously by a mass spectrometer (WSMR-1400; Westron, Chiba, Japan). The resistance of the inspiratory side was $0.059 \mathrm{kPa} / \mathrm{l} / \mathrm{s}$, while that of the expiratory circuit was $0.049 \mathrm{kPa} / \mathrm{l} / \mathrm{s}$. Subjects wearing nose clips were seated comfortably in front of the rebreathing circuit and held the mouthpiece in position. Initially they breathed air by a bypass of the rebreathing bag to room air until the circuit was equilibrated. They then rebreathed a gas mixture of $7 \%$ carbon dioxide and $93 \%$ oxygen from a six litre bag. During rebreathing the inspiratory side of the circuit was occluded randomly every $4-6$ breaths. Rebreathing was continued until the end tidal partial pressure of carbon dioxide $\left(\mathrm{PETCO}_{2}\right)$ reached about $8.7 \mathrm{kPa}$ or the subject complained of dyspnoea. The test was usually terminated within 3-4 minutes. Minute ventilation $(\dot{V} E)$ was calculated as the average of the two successive breaths preceding the one used for occlusion. Simultaneously the $\mathrm{PETCO}_{2}$ was measured. Hypercapnic response was assessed by the slopes of linear regressions between $\dot{V E}$ and PETCO $_{2}$ and between $P_{0.1}$ and $\operatorname{PETCO}_{2}\left(\Delta \dot{\mathrm{VE}} / \Delta\right.$ PeTCO $_{2}$ and $\Delta \mathrm{P}_{0.1} / \Delta$ PeTCO $_{2}$, respectively), calculated by the least squares method. Fifteen to 20 breath pairs were used for analysis.

Hypoxic ventilatory response (HVR) was measured by a modification of the progressive isocapnic hypoxia method of Rebuck and Campbell. ${ }^{12}$ Subjects rebreathed using the same rebreathing circuit as for the hypercapnic response, except the rebreathing bag contained eight litres of a gas mixture of $3.5 \%$ carbon dioxide, $23 \%$ oxygen, and $73.5 \%$ nitrogen and a bypass carbon dioxide absorber was used. During the test arterial oxygen saturation $\left(\mathrm{SaO}_{2}\right)$ was monitored with a pulse oximeter (Biox 3700, Ohmeda, Boulder, USA). During rebreathing $\mathrm{PETCO}_{2}$ was kept constant at the baseline resting level by removal of carbon dioxide from the circuit with a variable AC motor fan connected to a bypass carbon dioxide absorber. Rebreathing was continued until $\mathrm{SaO}_{2}$ decreased to $75-80 \%$. The hypoxic response was obtained from the slopes of linear regressions between $\dot{\mathrm{VE}}$ and $\mathrm{SaO}_{2}$ and between
$\mathrm{P}_{0.1}$ and $\mathrm{SaO}_{2}\left(\Delta \dot{\mathrm{V}} \mathrm{E} / \Delta \mathrm{SaO}_{2}\right.$ and $\Delta \mathrm{P}_{0.1} / \Delta \mathrm{SaO}_{2}$, respectively).

\section{RESPIRATORY MUSCLE STRENGTH}

As we had previously found that fenoterol increased the strength of the fatigued canine diaphragm, ${ }^{13}$ respiratory muscle strength was assessed by measuring mouth pressures during maximal static inspiratory (PImax) and expiratory (PEmax) efforts against a closed valve with a small air leak to prevent glottic closure. ${ }^{14}$ PImax was measured at FRC and residual volume (RV) and PEmax was measured at FRC and total lung capacity (TLC) with a differential pressure transducer (Validyne MP -45 $\pm 250 \mathrm{~mm} \mathrm{Hg}$ ). The determinations of PImax and Pemax were repeated until three measurements varying by $<5 \%$ and sustained for $>2$ seconds were recorded; the highest value thus obtained was reported.

\section{PROTOCOL}

The study was performed at the same time of day on two different days at least two days apart and within a seven day interval. Subjects were instructed to refrain from caffeine-containing beverages, alcohol, and other drugs for 24 hours before the study. HCVR was examined in all subjects while HVR was measured in seven of the 11 subjects. On each test day the baseline measurements of pulse rate (PR), blood pressure (BP), ventilation and $\mathrm{PETCO}_{2}$ were performed at rest. Either $5 \mathrm{mg}$ fenoterol (Boehringer Ingelheim of Japan, Kawanishi, Japan) or placebo was then administered orally in a randomised, double blind, crossover design on the first or second day. Two hours after fenoterol or placebo administration, pulmonary function tests, respiratory muscle strength, heart rate, blood pressure, ventilation, and $\mathrm{PETCO}_{2}$ were measured and HCVR and HVR were then calculated. For HVR PETCO $_{2}$ was controlled at the baseline level before administration of fenoterol or placebo because fenoterol could decrease $\mathrm{PETCO}_{2}$. The order of the tests (HCVR and HVR) was randomised and at least 10 minutes was allowed between tests.

\section{DATA ANALYSIS}

HCVR and HVR varied by approximately $20 \%$ and the sample size required to discern a significant difference from the drug was 10. All values are expressed as the mean (SD). Statistical analysis was performed using the Wilcoxon signed rank test and the two way analysis of variance (ANOVA). A p value of $<0.05$ was considered significant.

\section{Results}

Fenoterol did not affect $\mathrm{FEV}_{1}, \mathrm{VC}, \mathrm{FRC}$, or sGaw. Heart rate was increased by $8.0(10.5) \%$ (ANOVA, p<0.05) although systemic blood pressure did not change. Baseline minute ventilation while breathing air and VT/TI were both increased by $15 \%$ with fenoterol $(p<0.01)$. 

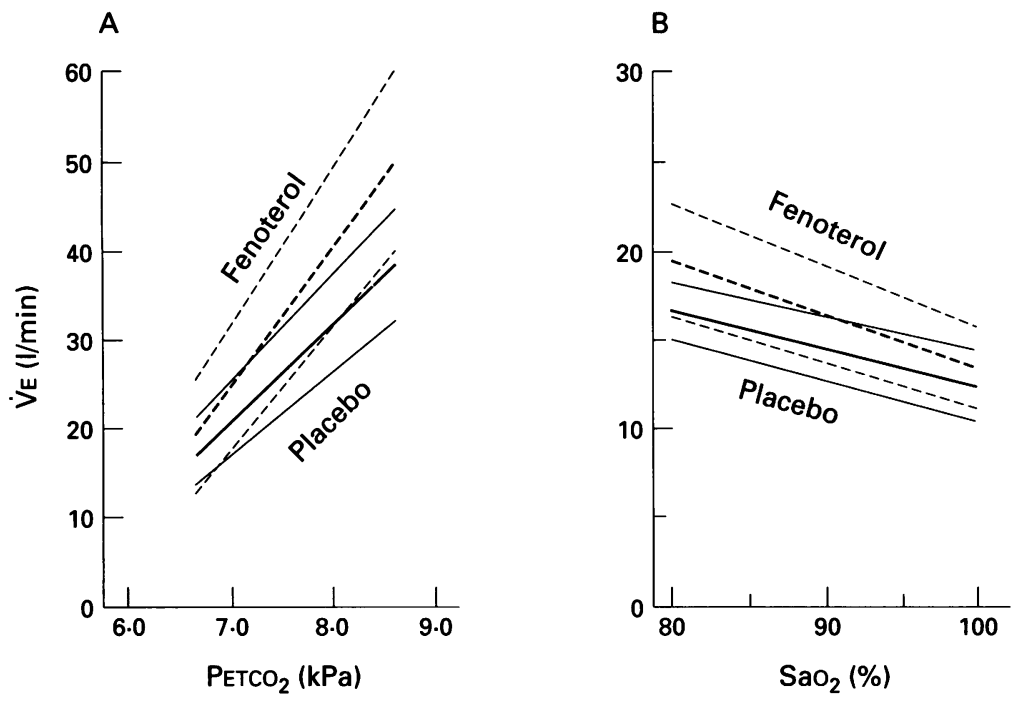

Figure 1 Mean $(A)$ hypercapnic and (B) hypoxic ventilatory responses (HCVR and HVR). Fenoterol treatment (dashed line) increased both HCVR and HVR compared with placebo (solid line). Average response curves were calculated from slope means $\left(\triangle \dot{V}_{E} /\right.$ $\triangle P_{E T C O}$ and $\triangle \dot{V}_{E} / \triangle \mathrm{SaO}_{2}$ ), and mean $\dot{V} E$ values (at $\mathrm{PETCO}_{2}$ of $8 \mathrm{kPa}$ with $\mathrm{HCVR}$ and at $80 \% \mathrm{SaO}_{2}$ with $\mathrm{HVR}$, respectively). Mean responses and $95 \%$ confidence intervals are represented by thick and thin lines, respectively.
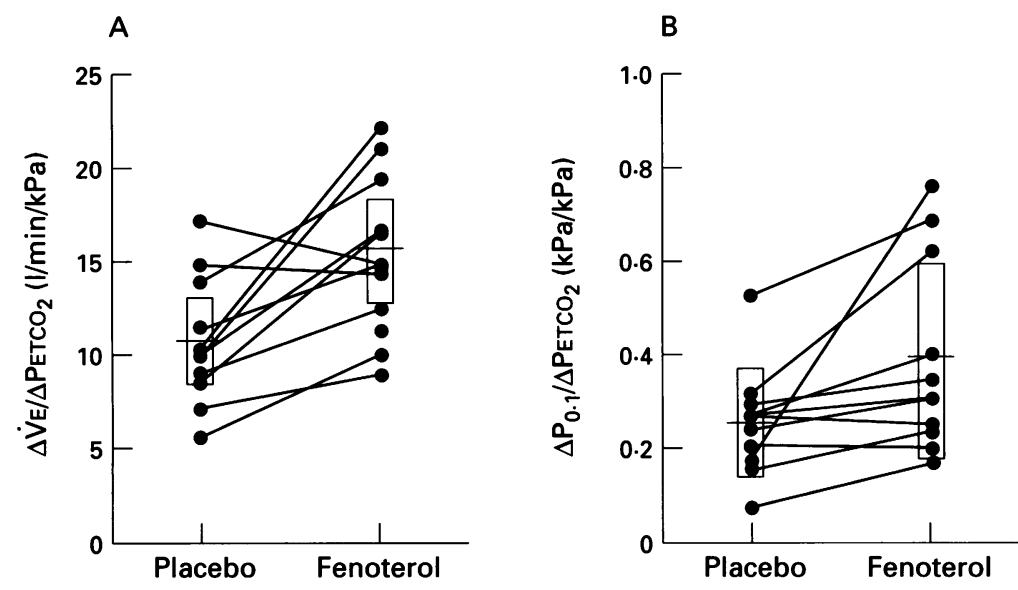

Figure 2 Hypercapnic ventilatory response (HCVR). (A) Slope of $\dot{V}$ E versus $P_{E T C O}$ curve $\left(\triangle V_{E} / \triangle P E T C O_{2}\right)$ with placebo and fenoterol. (B) Slope of $P_{0.1}$ versus $P_{E T C O}$ curve $\left(\triangle P_{0.1} / \triangle P E T C O_{2}\right)$ with placebo and fenoterol. Open boxes and bars represent the $95 \%$ confidence interval and mean value, respectively. Fenoterol increased the slopes of the response curve of $\dot{V} E$ by $56 \%(p<0 \cdot 01)$ and that of $P_{0.1}$ by $104 \%(p<0 \cdot 01)$.
A

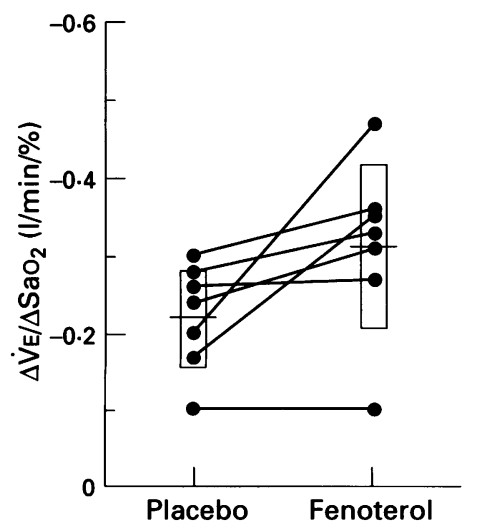

B

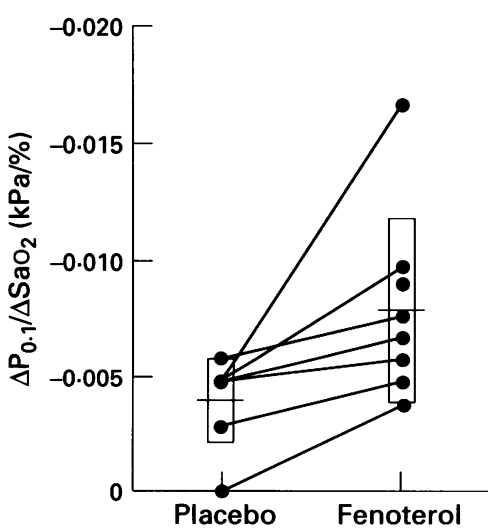

Figure 3 Hypoxic ventilatory response (HVR). (A) Slope of $\dot{V} E$ versus $\mathrm{SaO}_{2}$ curve $\left(\triangle \mathrm{VE} / \mathrm{SaO}_{2}\right)$ with placebo and fenoterol. $(B)$ Slope of $P_{0.1}$ versus $\mathrm{SaO}_{2}$ curve $\left(\Delta P_{0.1}\right.$ $\mathrm{SaO}_{2}$ ) with placebo and fenoterol. Open boxes and bars represent the $95 \%$ confidence interval and mean value, respectively. Both slopes of the hypoxic response curve increased $(p<0.05)$.
However, after drug treatment $\mathrm{PeTCO}_{2}$ did not differ between those given placebo and those given fenoterol $(5.05(0.38) v 4.89(0.62) \mathrm{kPa})$. Further, the $P_{0.1}$ during breathing air did not differ between treatments $(0.197(0.105) v$ $0 \cdot 243(0 \cdot 153) \mathrm{kPa})$. There was no difference in PImax or PEmax between the two treatments.

For HCVR fenoterol increased the slope of $\dot{\mathrm{V} E}$ to $\mathrm{PETCO}_{2}\left(\Delta \dot{\mathrm{VE}} / \Delta \mathrm{PeTCO}_{2}\right)$ by $52(43) \%$ $(\mathrm{p}<0.01)$ and that of $\mathrm{P}_{0.1}$ to $\operatorname{PETcO}_{2}\left(\Delta \mathrm{P}_{0.1} /\right.$ $\triangle$ PETCO $\left._{2}\right)$ by $71(104) \%$ compared with placebo $(\mathrm{p}<0.05)$ (figs 1 and 2). VE at PETCO $_{2}$ of $60 \mathrm{~mm}$ $\mathrm{Hg}(\approx 8 \mathrm{kPa})$ was $39.6(12.6) \mathrm{l} / \mathrm{min}$ with fenoterol, which was higher than the value with placebo $(31.2(7.6) 1 / \mathrm{min})(\mathrm{p}<0.01) . \mathrm{P}_{0.1}$ at PETCO $_{2}$ of $8 \mathrm{kPa}(0.70(0.35) \mathrm{kPa})$ after fenoterol was higher than after placebo $(0.54$ $(0.21) \mathrm{kPa})(\mathrm{p}<0.05)$.

For HVR fenoterol increased the slope of $\dot{V}_{E}$ to $\mathrm{SaO}_{2}\left(\Delta \dot{\mathrm{VE}} / \Delta \mathrm{SaO}_{2}\right)$ by $44.5(53.4) \% ; \mathrm{p}<0.05$ (fig 1). It also increased the slope of $\mathrm{P}_{0.1}$ to $\mathrm{SaO}_{2}\left(\Delta \mathrm{P}_{0.1} / \Delta \mathrm{SaO}_{2}\right)\left(-4 \cdot 1(2 \cdot 0) \times 10^{-3}\right.$ with placebo $v-8.0(4.3) \times 10^{-3} \mathrm{kPa} / \%$ with fenoterol, $\mathrm{p}<0.05$ ) (fig 3 ). The position of the $\dot{\mathrm{V}} v \mathrm{SaO}_{2}$ curve at $\mathrm{SaO}_{2}$ of $80 \%$ was higher than that of placebo $(16.7(1.8) v 19.5(3.5) \mathrm{l} /$ min, $\mathrm{p}<0.05)$. Similarly, fenoterol shifted the $\mathrm{P}_{0.1}$ curve to a higher $\mathrm{P}_{0.1}$ at $\mathrm{SaO}_{2}$ of $80 \%(0.29$ $(0.17) v 0.38(0.20) \mathrm{kPa}, \mathrm{p}<0.02)$.

\section{Discussion}

We have demonstrated that a single oral dose of $5 \mathrm{mg}$ fenoterol enhanced the ventilatory responses to both hypercapnia and hypoxia in normal subjects. Respiratory muscle strength and specific airway conductance were not changed. These data suggest that fenoterol stimulates both central and peripheral chemoreceptors, although it is unknown whether its action is direct or indirect.

We measured the ventilatory response two hours after oral administration of the drug to allow the plasma concentration of fenoterol to reach a maximum. ${ }^{15}$ Since VE reflects the neural output to inspiratory muscles poorly when thoracic mechanics change, ${ }^{16}$ we used occlusion pressure $\left(\mathrm{P}_{0.1}\right)$ as a reflection of respiratory output. ${ }^{11}$ Occlusion pressure may be affected by inspiratory muscle strength or lung volume. ${ }^{17}$ Fortunately, in this study neither FRC nor inspiratory muscle strength was affected by fenoterol treatment. Therefore, it is possible that both occlusion pressure and minute ventilation reflected the neural output of the respiratory centre in this study.

Fenoterol is a potent bronchodilator and may increase $\mathrm{FEV}_{1}$ and sGaw even in normal subjects. Resistive unloading with helium/oxygen breathing decreased $P_{0.1}$ but inhalation of atropine did not change $P_{0.1}$ in spite of a reduction in airways resistance. ${ }^{18}$ The increase in sGaw after fenoterol could therefore reduce the neural output such as $P_{0.1}$ or ventilation. In the present study, however, fenoterol caused no change in sGaw or $\mathrm{FEV}_{1}$. Thus fenoterol may not affect $P_{0.1}$ by changing airway mechanics. It is likely that fenoterol increases the neural output to the inspiratory muscles. 
Fenoterol increased the slopes of $\dot{V} E$ and $P_{0.1}$ in HVR. The activity of the carotid body chemoreceptors increases with decreasing $\mathrm{PaO}_{2}{ }^{19}$ Isoprenaline is known to stimulate the carotid body through a $\beta$ adrenergic mechanism. ${ }^{1-356}$ Fenoterol is a selective $\beta_{2}$ adrenergic agonist but also has weak $\beta_{1}$ activity. ${ }^{20}$ In the present study fenoterol did not affect the resting level of $\mathrm{PETCO}_{2}$ so that the level of carbon dioxide did not affect HVR. It is therefore possible that fenoterol augmented the response of the carotid body in hypoxia, probably through $\beta_{1}$ activity. The heart rate increased by $8 \%$ after fenoterol, which is also known to increase cardiac output, ${ }^{21}$ and this in turn may increase ventilation. ${ }^{22}$

Fenoterol increased HCVR as measured by $P_{0.1}$ and $\dot{V}_{E}$. Response to carbon dioxide inhalation is thought to occur through the stimulation of the medullary chemoreceptors in hyperoxia. Carbon dioxide also stimulates the peripheral chemoreceptors, but their contribution to overall stimulation by carbon dioxide is thought to be small in the presence of hyperoxia. ${ }^{23}$ It is possible that fenoterol stimulates the central chemoreceptors, thereby increasing HCVR.

$\beta$ adrenergic agonist actions are accompanied by an increase in metabolic activity. ${ }^{24}$ Although we did not measure oxygen consumption in our study, fenoterol increased resting VE without any changes in PETCO $_{2}$ and $\mathrm{P}_{0.1}$, suggesting that it raises the metabolic activity thus increasing resting VE. It is known that the increased metabolic rate, which is associated with hyperthyroidism, exercise, or feeding, may stimulate peripheral and/or central chemoreceptors. ${ }^{25-27}$

In conclusion, fenoterol stimulates ventilatory chemosensitivity although it is unknown whether the mechanisms are the direct $\beta$ receptor mediated effects on peripheral and/or central chemoreceptors, or the indirect effects on factors such as metabolic rate. Fenoterol is a potent bronchodilator and may be beneficial in patients with chronic obstructive pulmonary disease who have a tendency toward hypercapnia. However, further clinical studies are needed.

1 Heistad DD, Wheeler RC, Mark AL, Schmid PG, Abboud FM. Effects of adrenergic stimulation on ventilation in man. $\mathcal{F}$ Clin Invest 1972;51:1469-75.
2 Keltz H, Samortin T, Stone DJ. Hyperventilation: a manifestation of exogenous $\beta$-adrenergic stimulation. Am Rev Respir Dis 1972;105:637-40

3 Wasserman K, Mitchell RA, Berger AJ, Casaburi R, Davis JA. Mechanism of isoproterenol hyperpnea in the cat. Respir Physiol 1979;38:359-76.

4 Winn R, Hildebrandt JR, Hildebrandt J. Cardiorespiratory responses following isoproterenol injection in rabbits. $\mathcal{f}$ Appl Physiol 1979;47:352-9.

5 Eldridge FL, Gill-Kumar P. Mechanisms of hyperpnea induced by isoproterenol. Respir Physiol 1980;40:349-63.

6 induced by isoproterenol. Respir Physiol 1980;40:349-63. body chemoreceptor responses by isoproterenol in the cat. body chemoreceptor responses by

7 Leitch AG, Clancy LJ, Costello JE, Flenley D. Effect of intravenous infusion of salbutamol on ventilatory response to carbon dioxide and hypoxia and on heart rate and plasma potassium in normal men. BMf 1976;1:365-7.

8 Grogaard J, Sundell $\mathrm{H}$. Effect of beta-adrenergic agonists on apnea relfexes in newborn lambs. Pediatr Res 1983;17: 213-9.

9 Folgering $\mathrm{H}$. Central $\beta$-adrenergic effects on the control of ventilation in cats. Respiration 1980;39:131-8.

10 Read DJC. A clinical method for assessing the ventilatory response to carbon dioxide. Australas Ann Med 1967;16: $20-32$.

11 Whitelaw WA, Derenne JP, Milic-Emili J. Occlusion pressure as a measure of respiratory centre output in conscious man. Respir Physiol 1975;23:181-99.

12 Rebuck AS, Campbell EJM. A clincal method for assessing the ventilatory response to hypoxia. Am Rev Respir Dis 1974;109:345-50.

13 Suzuki S, Numata H, Sano F, Yoshiike Y, Miyashita A, Okubo T. Effects and mechanism of fenoterol on fatigued canine diaphragm. Am Rev Respir Dis 1988:137:1048-54.

14 Blin Liaphragm. Am Rev Respir Dis 1988,137:1048-54. values and relationship to age and sex. Am Rev Respir Dis values and relation

15 Rominger KL, Pollmann W. Comparative pharmacokinetic studies on fenoterol-hydrobromide in rat, dog and man. studies on fenoterol-hydrobromide

16 Cherniack RM, Snidal DP. The effect of obstruction to breathing on the ventilatory response to $\mathrm{CO}_{2}$. $\mathcal{F}$ Clin Invest 1956;35:1286-90.

17 Eldridge FL, Vaughn KZ. Relationship of thoracic volume and airway occlusion pressure: muscular effects. $\mathcal{F} A p p l$ Physiol 1977;43:312-21.

18 DeWeese El, Sullivan TY, Yu PL. Neuromuscular response to resistive unloading: helium vs. bronchodilatation. $\mathscr{f}$ Appl Physiol 1984;56:1308-13.

19 Hornbein TF. The relation between stimulus to chemoreceptors and their response. In: Torrance RW, ed. Arterial chemoreceptors. Oxford: Blackwell Scientific Publications, chemoreceptors.

20 Giles RE, Williams JC, Finkel MP. The bronchodilator and cardiac stimulant effects of Th1165a, salbutamol and isoproterenol. $\mathcal{f}$ Pharmacol Exp Ther 1973;186:472-81.

21 Chapman KR, Smith DL, Rebuck AS, Leenen FHH Hemodynamic effects of inhaled ipratropium bromide, alone and combined with an inhaled beta ${ }_{2}$-agonist. $A m$ Rev Respir Dis 1985;132:845-7.

22 Wasserman K, Whipp BJ, Castagna J. Cardiodynamic hyperpnea: hyperpnea secondary to cardiac output increase. $\mathcal{A}$ Appl Physiol 1974;36:457-64.

23 Gelfand R, Lambertsen CJ. Dynamic respiratory response to abrupt change of inspired $\mathrm{CO}_{2}$ at normal and high $\mathrm{Po}_{2}$ to abrupt change of inspired CO

24 Amoroso P, Wilson SR, Moxham J, Ponte J. Acute effects of inhaled salbutamol on the metabolic rate of normal

25 Zwillich CW, Sahn SA, Weil JV. Effects of hypermetabolism on ventilation and chemosensitivity. $\mathcal{F}$ Clin Invest 1977 60;900-6.

26 Weil JV, Byrne-Quinn E, Sodal IE, Kline JS, McCullough RE, Filey GF. Augmentation of chemosensitivity during mild exercise in normal man. 7 Appl Physiol 1972;33: 813-9.

27 Engel LA, Ritchie B. Ventilatory response to inhaled carbon dioxide in hyperthyroidism. $₹$ Appl Physiol 1971;30:173-7. 